NASA

Technical Memorandum 107012
Army Research Laboratory

Technical Report ARL-TR-838

\title{
Bending Strength Model for Internal Spur Gear Teeth
}

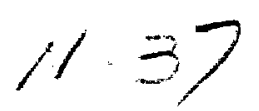

M. Savage and K.L Rubadeux

The University of Akron

Akron, Ohio

and

(NASA-TM-107012) BENDING STRENGTH MOUEL FOR INTERNAL SPUR GEAR TEETH

N95-33908

H.H. Coe

(NASA. Lewis Research Center) $12 p$

Unclas

Lewis Research Center

Cleveland, Ohio

Prepared for the

31st Joint Propulsion Conference and Exhibit cosponsored by AIAA, ASME, SAE and ASEE

San Diego, California, July 10-12, 1995
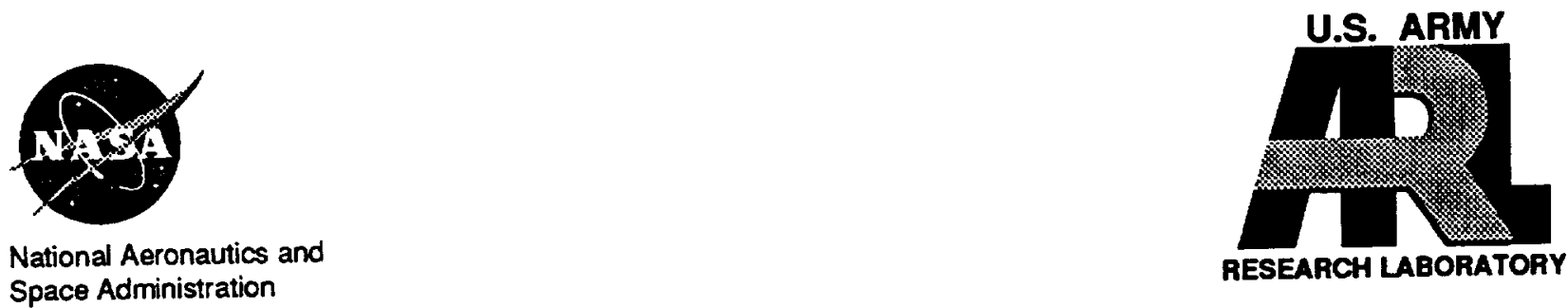


\author{
M. Savage \\ K. L. Rubadeux \\ The University of Akron \\ Akson, Ohio 44325 \\ phone (216) $972-7737$ \\ fax (216) $972-6027$
}

H. H. Coe

NASA Lewis Research Center

Cleveland, Ohio 44135

\begin{tabular}{|c|c|c|}
\hline Abstract & $f$ & face width (mm.in) \\
\hline & $h$ & height of Lewis parabola (mm,in) \\
\hline $\begin{array}{l}\text { Internal spur gear teeth are normally } \\
\text { stronger than pinion teeth of the same pitch }\end{array}$ & $\mathrm{H}$ & height, y distance (mm,in) or stress \\
\hline and face width since external teeth are & J & $\begin{array}{l}\text { Tation constant } \\
\text { ending strength factor }\end{array}$ \\
\hline $\begin{array}{l}\text { smaller at the base. However, ring gears } \\
\text { which are narrower, have an unequal }\end{array}$ & $\sqrt{1}$ & \\
\hline $\begin{array}{l}\text { which are narrower, have an unequal } \\
\text { addendum or are made of a material with a }\end{array}$ & $\begin{array}{l}K_{f} \\
m\end{array}$ & $\begin{array}{l}\text { stress concentration factor } \\
\text { module }(\mathrm{mm})\end{array}$ \\
\hline lower strength than that of the meshing pinion & $N$ & number of teeth \\
\hline may be loaded more critically in bending. In & $P_{d}$ & diametral pitch (1.0/inch) \\
\hline $\begin{array}{l}\text { this study, a model for the bending strength of } \\
\text { an internal gear tooth as a function of the }\end{array}$ & $R$ & pitch radius (mm, in) \\
\hline $\begin{array}{l}\text { applied load pressure angle is presented } \\
\text { which is based on the inscribed Lewis constant }\end{array}$ & $R_{C}$ & $\begin{array}{l}\text { radial distance to the parabola apex } \\
\text { (mm,in) }\end{array}$ \\
\hline strength parabolic beam. The bending model & $R_{F}$ & cutter tip radius (mm,in) \\
\hline $\begin{array}{l}\text { includes a stress concentration factor and an } \\
\text { axial compression term which are extensions of } \\
\text { the model for an external gear tooth. The }\end{array}$ & $R_{C}^{R_{F}}$ & $\begin{array}{l}\text { radius to trochoid point (mm,in) } \\
\text { cutter radius to center of cutter tip } \\
\text { (mm,in) }\end{array}$ \\
\hline $\begin{array}{l}\text { geometry of the Lewis factor determination is } \\
\text { presented. the iteration to determine the } \\
\text { factor is described and the bending strength } J\end{array}$ & $R_{T}$ & $\begin{array}{l}\text { gear radius to the center of the cutter tip } \\
\text { fillet }(\mathrm{mm}, \mathrm{in})\end{array}$ \\
\hline $\begin{array}{l}\text { factor is compared to that of an external gear } \\
\text { tooth. This strength model will assist optimal }\end{array}$ & RA & $\begin{array}{l}\text { distance from the cutting pitch point to } \\
\text { the cut point ( } \mathrm{mm} \text {, in) }\end{array}$ \\
\hline $\begin{array}{l}\text { design efforts for unequal addendum gears } \\
\text { and gears of mixed materials. }\end{array}$ & RD & $\begin{array}{l}\text { distance from the cutting pitch point to } \\
\text { the center of the cutter tip fillet (mm,in) }\end{array}$ \\
\hline Nomenclature & $t_{c}$ & Lewis parabola tooth thickness (mm,in) \\
\hline & $w_{t}$ & $\begin{array}{l}\text { pitch circle tooth thickness (mm,in) } \\
\text { tangential load (kN,lbs) }\end{array}$ \\
\hline Symools & $x$ & Lewis form factor distance (mm,in) \\
\hline gear dedendum (mm,in) & $\mathrm{x}$ & abscisso coordinate (mm,in) \\
\hline c center distance (mm,in) & Y & $\begin{array}{l}\text { ordinate coordinate (mm.in) or Lewis form } \\
\text { factor }\end{array}$ \\
\hline Copyright $\odot 1995$ by Michael Savage. & $\alpha$ & angle between the tangent to the \\
\hline Published by the American Institute of & & trochoid and the tooth centerline \\
\hline $\begin{array}{l}\text { Aeronautics and Astronautics, Inc. with } \\
\text { permission. }\end{array}$ & $\beta$ & $\begin{array}{l}\text { (radians) } \\
\text { central gear angle (radians) }\end{array}$ \\
\hline
\end{tabular}


$Y$ angle on the gear from the cutting pitch point to the trochoid cutting point (radians)

$\delta_{1}$ angle on the cutter from the pitch point on the tooth surfoce to the center of the tip circle (radians)

$\delta_{2}$ angle on the gear from the pitch point on the tooth surface to the center of the tip circle (radians)

$\Delta$ internal tooth half bottom land angle (radians)

$\eta \quad$ angle at the cutting point between the line of centers and the normal through the tip fillet center (radians)

$\theta$ roll angle (radians)

$\theta_{f}$ central angle on the gear from the center of the tip of the trochoid to the trochoid point (radians)

$\theta_{\mathrm{ft}}$ central angle on the gear from the center of the gear tooth to the trochoid point [radians)

$\lambda$ supplement of the angle $\alpha$ (radians)

$\rho$ radius of curvature ( $\mathrm{mm}$, in)

$\sigma$ bending stress (Pa. psi)

$\Phi$ pressure angle (radians)

$\Psi$ slope of the trochoid at the contact point

\section{Subscripts}

A point of contact
b base circle
C apex of parabola
E involute point
$f$ fillet
$F$ trochoid point
$z$ of the involute at the cutter tip fillet center
1 cutter
2 internal gear

\section{Superscripts}

$L \quad$ stress concentration equation constant $M$ stress concentration equation constant
Introduction

In the design of spur gear teeth, bending strength is a significant concern ${ }^{1.23}$. Gear teeth which break off at the root become free debris in a gear box to cause secondary failures. In a very short time, a tooth bending fatigue failure will cause a complete breakdown of the transmission in which it occurs. So tooth bending fatigue limits in a transmission are a primary concern in all stages of design.

For equal addenda gears made of the same material and the same width, the pinion teeth have the lowest bending fatigue limit since their bases are smaller and the loads on the pinion and gear teeth are equal. Thus most of the gear tooth bending stress models are for external gear teeth ${ }^{4.5}$. However, there are situations in which an internal gear tooth may have a higher chance of failure than its meshing external pinion tooth. It may be made of a weaker material or its tooth thickness may be reduced to enlarge the pinion's tooth thickness and balance the bending strengths in the mesh.

Present models for the bending strength of internal gear teeth ${ }^{6.7}$ use the straight line tangent model of Hofer with a slope relative to the tooth centerline of forty-two to fifty-nine degrees. Both studies recommend forty-five degrees for thick rimmed gears with larger angles for thin rimmed gears. The AGMA Aerospace Gearing Design Guideline Annex". gives a procedure for finding the inscribed parabola which yields the highest stress estimate for a given tooth and loading. This procedure assumes a solid body gear and a circular fillet tangent to the tooth involute.

In this work, the classic method of inscribing a constant strength parabola inside the tooth is used to estimate the tooth strength?. This is the method of Wilfred Lewis ${ }^{10}$ which has been used for many years by the AGMA as the basis of the external gear tooth strength model ${ }^{3}$. A stress concentration factor has been added to the calculation as an extension of the Dolan and Broghamer 
factor". The model also includes axial compression to match the AGMA bending strength $\mathrm{J}$ factor. Required information to specify the internal gear $J$ factor are: 1 ) the dedendum ratio of the tooth, 2) the nominal pressure angle, 3) the pitch circle tooth thickness, 4) the number of teeth on the internal gear, 5) the number of teeth on the meshing pinion to find the highest point of single tooth loading, 6) the number of teeth on the pinion shaper cutter, and 7) the tip radius of the cutter.

\section{Tooth Strength Mode}

Wilfred Lewis developed the basic model for bending stress in gear teeth in $1892^{10}$. In his analysis, Lewis considered a gear tooth to be a loaded cantilever beam with a force applied to the tip of the gear. He made the following assumptions:

1. the load is applied to the tip of a gear tooth:

2. only the tangential component of the force will be a factor (the radial component is neglected):

3. the load is distributed uniformly across the entire face width of the gear,

4. forces due to tooth sliding friction are negligible; and

5. no stress concentration is present in the tooth fillet.

Lewis took into account the geometry of the gear tooth by inscribing a constant strength parabola within the tooth form. The vertex of the parabola is located at the intersection of the tooth centerline and the applied load's line of action. At the location on the profile of the tooth where the inscribed parabola is tangent, the Lewis equation for the tooth bending stress is expressed as:

$$
\sigma=\frac{W_{t} \cdot P_{d}}{f \cdot Y}
$$

where $W_{t}$ is the tangential load on the tooth. $P_{d}$ is the diametral pitch, $f$ is the gear face width, and $Y$ is the Lewis form factor based on the geometry of the tooth. The point of application of the load is described by the pressure angle of the applied load at the tooth surface. $\phi_{A}$.

For the stress analysis of internal gears, both involute and trochoid geometry are used in checking for the smallest inscribed parabola in the tooth.

\section{Involute Geometry}

The involute is the locus of a point on a line unrolling from its base circle. The involute profile is described in terms of a coordinate frame with its center at the gear center and the $y$ axis through the center of the tooth. The coordinates of the profile are obtained as projections of the base radius, $R_{b 2}$, and the radius of curvature. $\rho_{\mathrm{E}}$, of the involute point onto this $x, y$ coordinafe frame.

The involute function of a pressure angle. $\phi$, depicted in Figure 1 , is the difference between the roll angle and the pressure angle at that point. Mathematically, the involute of an angle is expressed as:

$$
\operatorname{INV}(\phi)=\theta-\phi=\tan (\phi)-\phi
$$

The pitch radius of the internal gear is expressed by the equation:

$$
R_{2}=\frac{N_{2}}{2 \cdot P_{d}}
$$

or

$$
R_{2}=N_{2} \cdot \frac{m}{2}
$$

for metric units, where $\mathrm{N}_{2}$ is the number of internal gear teeth, $P_{d}$ is the diametral pitch and $m$ is the module. The base radius is:

$$
R_{b 2}=R_{2} \cdot \cos (\phi)
$$

Delta, $\Delta$, is one half of the bottom land angle of the tooth involute. In Figure 1, $\Delta$ can be seen as the angle from the center of the tooth to the involute at the base circle, which is: 


$$
\Delta=\frac{t_{p}}{2 \cdot R_{2}}-\operatorname{INV}(\Phi)
$$

where $t_{p}$ is the tooth thickness at the pitch circle.

As shown in Figure 2, the radius to the loaded line of action at the centerline of the loaded tooth is $R_{\text {. }}$. This is also the radial distance to the parabola apex. The pressure angle at $R$ is equal to the sum of the tangent of $\Phi_{A}$, the pressure angle at the tooth surface. and $d$. So $R_{C}$ can be expressed as:

$$
R_{C}=\frac{R_{b 2}}{\cos \left(\phi_{C}\right)}=\frac{R_{b 2}}{\cos \left(\tan \left(\phi_{A}\right)+\Delta\right)}
$$

In Figure 3, $\theta$ is the roll angle to the point on the involute which is tangent to the inscribed parabola with its apex at $R$. Since we must iterate to find $\theta$, an initial esfimate for $\theta$ can be expressed as:

$$
\theta=1.5 \cdot \tan \left(\phi_{A}\right)
$$

$X_{E}$ and $Y_{F}$ are the coordinates of the involute point which is cut at the roll angle $\theta$. These coordinates are measured with respect to the center of the loaded tooth. From the geometry of figure $3, X_{E}$ and $Y_{E}$ are:

$$
\begin{aligned}
& X_{E}=\rho_{E} \cdot \cos (\Delta+\theta)-R_{b 2} \cdot \sin (\Delta+\theta) \\
& Y_{E}=\rho_{E} \cdot \sin (\Delta+\theta)+R_{b 2} \cdot \cos (\Delta+\theta)
\end{aligned}
$$

In Figure 3, $\mathrm{H}_{1}$ is the $y$ distance from the tangent point on the involute to the intersection of the involute's tangent with the tooth centerline.

$$
H_{1}=\frac{X_{E}}{\tan (\Delta+\theta)}
$$

$\mathrm{H}_{2}$ is the distance from that same point on the parabola to the intersection of the parabola's tangent with the tooth centerline. Since the $y$ distance to the apex of a parabola is one half the distance to the intersection of the tangent with the centerline, $\mathrm{H}_{2}$ can be expressed as:

$$
H_{2}=2 \cdot\left(Y_{E}-R_{C}\right)
$$

An interval halving iterative process is used to find the location on the tooth surface at which the largest parabola is tangent to the involute. $\theta, X_{F_{1}} Y_{E}, H_{1}$, and $H_{2}$ are calculated each time in this process. The angle $\theta$ is increased by a fixed step. $\Delta \theta$, in each iteration. with $\Delta \theta$ set to 0.01 radians initially. When the difference in $\mathrm{H}_{1}$ and $\mathrm{H}_{2}$ changes sign. $\Delta \theta$ is set to $-\Delta \theta / 2$ to close in on the solution. When the values of $H_{1}$ and $H_{2}$ are equal, the location on the tooth surface at which the largest parabola is tangent to the involute has been determined.

\section{Trochoid Geometry}

For an internal tooth, the largest inscribed parabola may be tangent to the involute or it may be tangent to the trochoid at the base of the tooth. Therefore, trochoid geometry is also used to find the point of maximum stress. In the following analysis, the cutter is gear 1 and the internal gear is gear 2 with $R_{1}$ being the pitch radius of the cutter and $R_{2}$ being the pitch radius of the internal gear.

As shown in Figure 4, $R_{0}$ is the cutter radius to the center of the cutter tip fillet:

$$
R_{O}=R_{1}+B-R_{F}
$$

where $B$ is the dedendum of the internal gear and $R_{F}$ is the cutter tip radius. The pressure angle on the cutter to the involute of the cutter tip fillet center is denoted by $\phi_{Z}$ and is:

$$
\phi_{Z}=\cos ^{-1}\left(\frac{R_{b l}}{R_{0}}\right)
$$

The radius of curvature of the involute at the cutter tip fillet center is $\rho_{7}$ which can be determined from $R_{O}$ and $\phi_{Z}$ by: 


$$
p_{Z}=R_{0} \cdot \sin \left(\phi_{Z}\right)
$$

$\delta_{1}$ is the angle on the cutter from the pitch point on the tooth surface to the center of the cutter tip fillet and $\delta_{2}$ is the conjugate rotation of the gear from the pitch point on the tooth surface to the center of the cutter tip fillet on the cutting trochoid. The angles $\delta_{1}$ and $\mathrm{\delta}_{2}$ can be calculated as:

$$
\begin{aligned}
& \delta_{1}=\frac{\rho_{Z}+R_{F}}{R_{b 1}}-\phi_{Z}-\mid N V(\phi) \\
& \delta_{2}=\delta_{1} \cdot \frac{R_{1}}{R_{2}}
\end{aligned}
$$

Figure 5 shows the paths of the trochoids on the internal gear tooth and also displays the locations of point $C$ on the trochoid of the tip center and its corresponding pitch point. D. The inner trochoid is for the point at the center of the cutter tip fillet. The outer trochoid is for the envelope of the cutter tip positions which is the cut shape on the tooth root. The line $\mathrm{O}_{2} \mathrm{C}$ locates the tooth centerline in these figures.

In Figure 5, $\theta_{1}$ is the rotation of the cutter and $\theta_{2}$ is the corresponding rotation of the gear. While the cutter rotates the center of the tip fillet from point $F$ to point $C$, the gear rotates the apex of the trochoid, which is a fillet radius above point $F$, to point $G$. The line $\mathrm{O}_{2} \mathrm{G}$ then is the centerline of the trochoid on the gear. The angular rotation of the gear can by expressed in terms of the rotation of the cutter as:

$$
\theta_{2}=\theta_{1} \cdot \frac{R_{1}}{R_{2}}
$$

$R_{T}$ is the radius from the gear center to the center of the cutter tip fillet. From triangle $A B C$ in Figure 6 and the law of cosines, $R_{T}$ can be defined as:

$$
R_{T}=\left[c^{2}+R_{O}^{2}+2 \cdot c \cdot R_{O} \cdot \cos \left(\theta_{i}\right)\right]^{1 / 2}
$$

where $c$ is the gear to cutter center distance which is equal to $R_{2}$ minus $R_{1}$. The angle $\beta$ is the central angle on the gear from the cutting pitch point, $D$, to the center of the cutter tip fillet. In Figure 6, the perpendicular distance from point $C$ to the gear-to-cutter line of centers is:

$$
R_{T} \cdot \sin (\beta)=R_{O} \cdot \sin \left(\theta_{1}\right)
$$

therefore,

$$
\beta=\sin ^{-1}\left(\frac{R_{0} \cdot \sin \left(\theta_{1}\right)}{R_{T}}\right)
$$

$R D$ is the distance from the cutting pitch point to the center of the cutter tip fillet. Applying the law of cosines to triangle ADC. yields:

$$
\left.R D=\left[R_{2}^{2}+R_{T}^{2}-2 \cdot R_{2} \cdot R_{T} \cdot \cos (\beta)\right]\right] / 2
$$

The angle at the cutting pitch point between the line of centers and the cutting normal through the tip fillet center, $n$. is found from the law of cosines in triangle ADC:

$$
n=\cos ^{-1}\left(\frac{R_{2}{ }^{2}+R D^{2}-R_{T}{ }^{2}}{2 \cdot R_{2} \cdot R D}\right)
$$

$R_{F F}$ is the radius from the gear center to the actual trochoid point:

$$
R_{F F}=\left[R_{2}{ }^{2}+R A^{2}-2 \cdot R_{2} \cdot R A \cdot \cos (\eta)\right]^{1 / 2}
$$

where RA equals RD plus $R_{F}$. Gamma, $y$, is the angle on the gear from the cutting pitch point to the trochoid cutting point:

$$
Y=\cos ^{-1}\left(\frac{R_{2}^{2}+R_{F F}^{2}-R A^{2}}{2 \cdot R_{2} \cdot R_{F F}}\right)
$$

An expression for $\theta_{f}$, the central angle on the gear from the cenfer of the tip of the trochoid to the trochoid point, is:

$$
\theta_{f}=\gamma-\theta_{2}
$$


In Figure $6, \theta_{f f}$ is the central angle on the gear from the cenfer of the gea tooth to the trochoid point. It can be expressed as the arc from the tooth centerline to the pitch point on the involute plus the arc from the pitch point to the center of the tip trochoid minus the arc to the trochoid point:

$$
\theta_{f t}=\frac{t_{p}}{2 \cdot R_{2}}+\delta_{2}-\theta_{f}
$$

The coordinates of the fillet developed on the internal gear are $X_{F}$ and $Y_{F}$ :

$$
X_{F}=R_{F} F \cdot \sin \left(\theta_{f} f\right)
$$

and

$$
Y_{F}=R_{F} F \cdot \cos \left(\theta_{f} \dagger\right)
$$

Psi, $\Psi$, is the slope of the trochoid at the contact point measured relative to a line perpendicular to the centerline of the tooth. The trochoid surfoce is normal to the line $D E$ in Figure 5 since $D$ is the instant center for the relative motion of the cutter with respect to the gear. In Figure 7, the angle at $E$ between the tangent to the trochoid and the radial line to $O_{2}$ is $n / 2-(\pi-y-n)$ or $y+n-\pi / 2$. This makes the angle between the tangent to the frochoid and the tooth centerline:

$$
\alpha=\pi-\theta_{f t}-(\gamma+n-\pi / 2)
$$

or

$$
\alpha=3 \pi / 2-\theta_{f t}-\gamma-\eta
$$

its supplement is

$$
\lambda=\pi-\alpha=\theta_{\mathrm{ft}}+\gamma+\eta-\pi / 2
$$

This angle is the complement of $\psi$, therefore:

$$
\Psi=\pi / 2-\left(-\pi / 2+\theta_{f t}+y+\eta\right)
$$

or

$$
\Psi=\pi-n-\gamma-\theta_{f \dagger}
$$

In Figure 7. $\mathrm{H}_{1}$ is the radial distance on the tooth centerline from the point of interest to where the trochoid tangent crosses the center of the tooth:

$$
H_{1}=X_{F} \cdot \tan (\Psi)
$$

$\mathrm{H}_{2}$ is defined as the radial distance on the tooth centerline from the point of interest to where the parabola tangent crosses the center of the tooth. Since one-half $\mathrm{H}_{2}$ equals $Y_{F}$ minus $R_{C}$ :

$$
H_{2}=2 \cdot\left(Y_{F}-R_{C}\right)
$$

A similar interval halving iterative process is used to find the location of the fillet developed on the internal gear which is tangent to a point on the inscribed parabola. When the values of $\mathrm{H}_{1}$ and $\mathrm{H}_{2}$ are equal, the location of the tangent point on the internal gear is determined.

The results obtained from the involute and trochoid geometries are then compared. The smaller $x$ coordinate identifies the weaker inscribed parabola for the internal tooth. This $x$ coordinate and its corresponding y coordinate are used to calculate the Lewis form factor. and the AGMA bending strength $\mathrm{J}$ factor which includes a stress concentration factor and a term for axial compression in the tooth.

\section{Bending Strength Factor}

The Lewis form factor, $Y$, originally defined for external teeth, is:

$$
Y=\frac{2}{3} \cdot P_{d} \cdot x
$$

where

$$
x=\frac{x_{E}{ }^{2}}{R_{C}-Y_{E}}=\frac{{ }_{C}{ }^{2}}{4 \cdot\left(R_{C}-Y_{E}\right)}
$$

One of the most important factors which Lewis overlooked in his analysis was the effect of stress concentrations. Large localized 
stresses occur in the fillets of gear teeth due to the sudden change in the cross-section of the tooth. By examining these factors and determining their exact effect on the bending stress in a gear tooth, Lewis' work was extended.

In 1940, professors T.J. Dolan and E.L. Broghamer of the University of Illinois used the photoelastic method of stress analysis to do this". They examined various types of gear teeth and determined the location and the magnitude of the maximum stresses which occur in the tooth fillets. Their research showed that the maximum stress is located closer to the root circle than Lewis had predicted. However, the distance between Lewis' location and Dolan's and Broghamer's location of the maximum stress is relatively small. Thus, the use of Lewis' model to determine the bending stress location in gear teeth was confirmed by Dolan and Broghamer. They also determined that the primary factors affecting the stress concentration at the tooth fillet are the fillet radius, the tooth thickness, the height of the load position on the tooth, and the tooth pressure angle. They developed the following stress concentration factor curve fit relation ${ }^{211}$ :

$$
K_{f}=H+\left(\frac{t_{c}}{\rho_{f}}\right)^{L} \cdot\left(\frac{t_{c}}{h}\right)^{M}
$$

where, $t$ is the tooth thickness at the critical section. $\mathcal{p}_{f}$ is the minimum radius of curvature of the fillet curve, and $h$ is the height of the Lewis parabola.

From a curve fit of the experimental data of Dolan and Broghamer, AGMA $A^{5}$ gives the following values for the constants $H, L$, and $M$ in terms of the pitch circle pressure angle, $\phi$ :

$$
\begin{aligned}
& H=0.331-0.436 \cdot \phi \\
& L=0.324-0.492 \cdot \phi \\
& M=0.261+0.545 \cdot \phi
\end{aligned}
$$

The modified Lewis model for determining the bending stress in gear teeth, which includes this stress concentration factor and a ferm for the axial compression in the tooth from the radial component of the tooth load, is:

$$
\sigma=\frac{W_{t} \cdot P_{d}}{f \cdot J}
$$

where the AGMA J factor, in terms of $\phi$, the pressure angle at the apex of the parabola on the tooth centerline, is:

$$
J=\frac{1}{k_{f} \frac{\cos \left(\phi_{c}\right)}{\cos (\phi)}\left(\frac{6 \cdot h}{t_{c}{ }^{2}}-\frac{\tan \left(\phi_{c}\right)}{t_{c}}\right)}
$$

Since the bending strength factor is a function of the tooth shape, it is dependent on the number of teeth on the gear. This is shown in Figure 8. which is a plot of the $\mathrm{J}$ foctor versus the number of gear teeth for both an external gear and for an internal gear. As the number of external gear teeth increases, the Lewis form factor increases at a decreasing rate: while as the number of internal gear teeth increases, the Lewis form factor decreases at a decreasing rate. Since the tooth shape on the two gears approach each other as the number of teeth increase, the form factor values for the internal and external gears approach each other as well.

\section{Conclusions}

An estimate for the bending strength of an internal spur gear tooth has been developed. This model uses the inscribed parabola approach of Wilfred Lewis in combination with an extrapolation of the Dolan and Broghamer stress concentration factor and the addition of an axial compression term.

The estimate is obtained considering both the involute surface of the tooth and the trochoid fillet at the base of the tooth as produced by a pinion shaper cutter. 
produced by a pinion shaper cutter. Generation equations are derived for both the involute and the trochoid. Due to the general nature of the model, the bending strength prediction is valid for a load applied at any point on the tooth. The load location is identified by the tooth surface pressure angle at the point of application of the load.

A direct and stable iteration procedure is used to determine the size of the largest inscribed parabola in the internal gear tooth. Based on the size of this parabola, the Lewis form factor is established.

To complement the base stress estimate. a stress concentration factor and an axial compression component are added to the strength model. This stress concentration factor is an extrapolation of the Dolan and Broghamer factor and is consistent with the AGMA J factor for external gears. A comparison of the bending strength model for an external gear and for an internal gear is given for gears of increasing size meshing with a twenty-five tooth pinion. Both gears have twenty-degree pressure angles and are cut with a twenty-tooth pinion shaper.

By improving the estimate of the bending strength of an internal gear tooth, this model will allow designers to vary the material of a ring gear from that of its meshing external gear. A long and short, addendum design system may also be evaluated to balance the bending strengths of the external and internal gears.

\section{References}

1. Buckingham, E. K., Analytical Mechanics of Gears, McGrow Hill, New York, 1949.

2. Drago, R. J., Fundamentals of Gear Design Butterworths, Stoneham. Massachusetts, 1988.

3. AGMA STANDARD, "Fundamental Rating Factors and Calculation Methods for Involute Spur and Helical Gear Teeth,"
ANSI/AGMA 2001-B88, Alexandria, Virginia, September 1988.

4. Mitchner, R. G. \& Mabie, H. H., "The Undercutting of Hobbed Spur Gear Teeth", ASME Joumal of Mechanical Desian Vol. 104. No. 1, 1982, pp. 148-158.

5. AGMA STANDARD, "Geometry Factors for Determining the Pitting Resistance and Bending Strength of Spur, Helical and Heringbone Gear Teeth." AGMA 908-B89. Alexandria, Virginia, April 1989.

6. von Eiff, H., Hirschmann, K. H. \& Lechner, G., "Influence of Gear Tooth Geometry on Tooth Stress of External and Internal Gears," ASME Journal of Mechanical Desian, Vol. 112, No. 4, 1990, pp. 575-583.

7. Miyachika. K. \& Oda, S., "Bending Strength of Internal Spur Gears," Proceedings of the International Conference on Motion and Power Transmissions, November 23-26. 1991. Hiroshima, Japan, pp. 781-786.

8. AGMA Information Sheet, "Spur Gear Geometry Factor Including Internal Meshes," Annex A, AGMA 911-A94, Design Guidelines for Aerospace Gearing. Alexandria, Virginia, 1994.

9. Rubadeux, K. L. "PLANOPT - a Forttan Optimization Program for Planetary Transmission Design." M.S. Thesis, The University of Akron, May, 1995.

10. Lewis, W., "Investigation of the Strength of Gear Teeth," Proceedings of the Engineers Club, Philadelphia, Pennsylvania, 1892.

11. Dolan, T. J. \& Broghamer, E. L., "A Photoelastic Study of Stresses in Gear Tooth Fillets," University of Illinois, Engineering Experiment Station, Bulletin No. $335,1942$. 


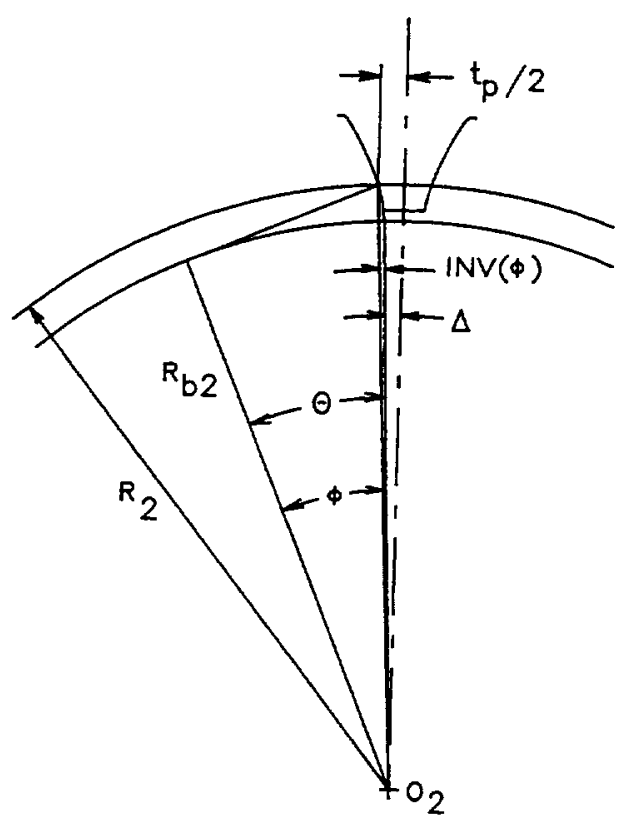

Figure 1 Involute and Top Land Angles for an Internal Gear Tooth

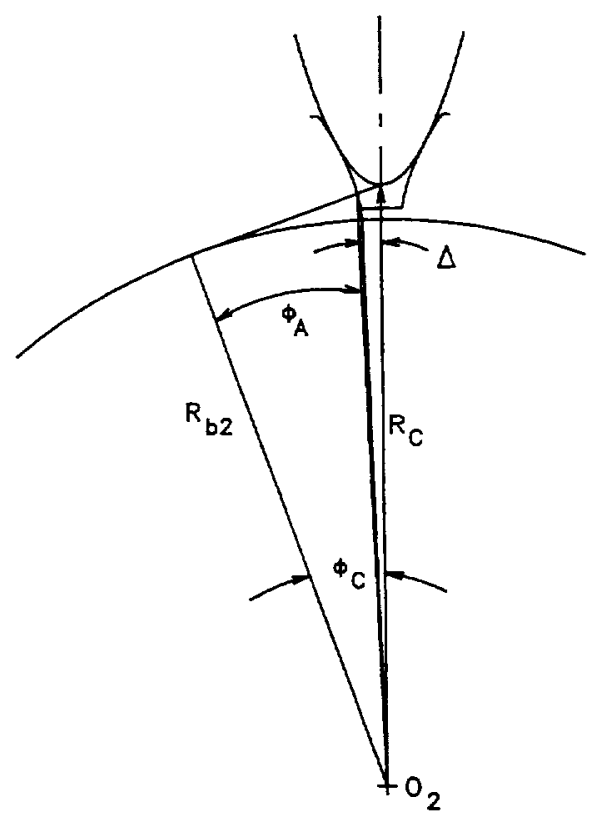

Figure 2 Location of the Parabola Apex on the Internal Gear Tooth

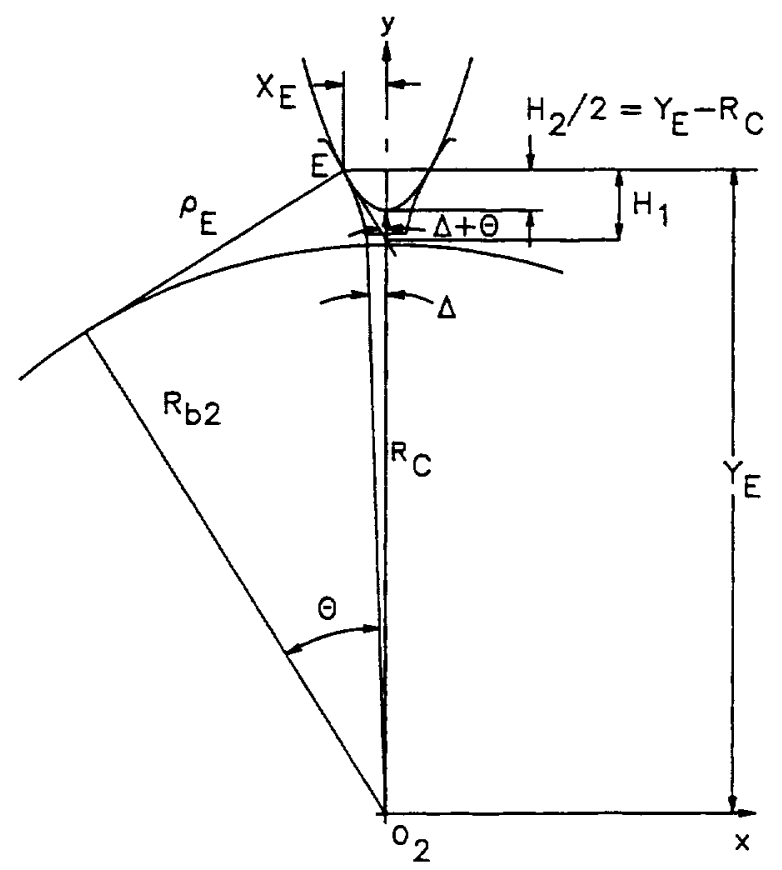

Figure 3 Involute Coordinate Geometry for an Internal Gear Tooth

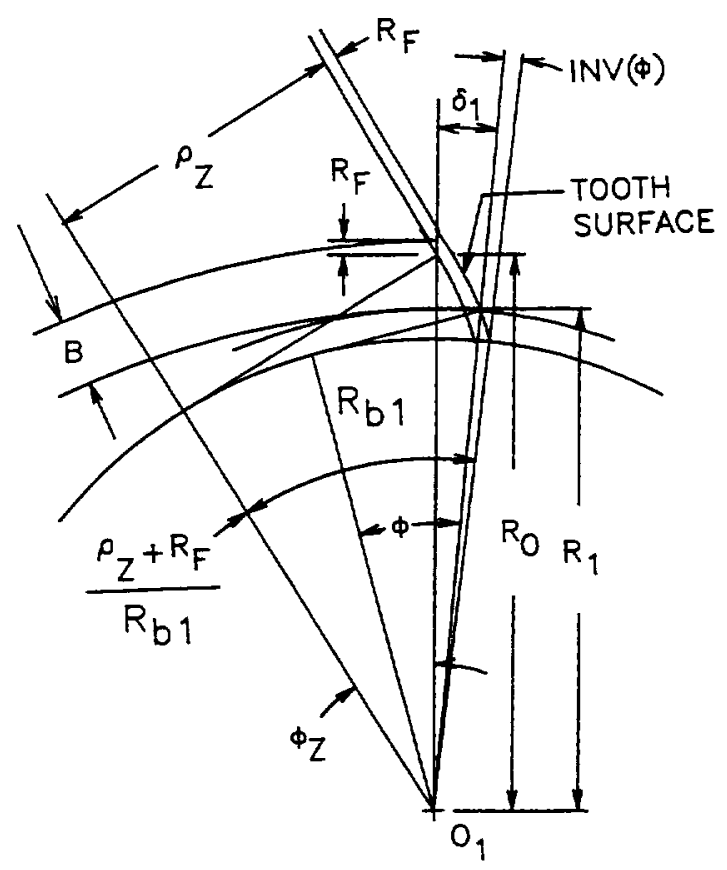

Figure 4 Cutter Tip Geometry 


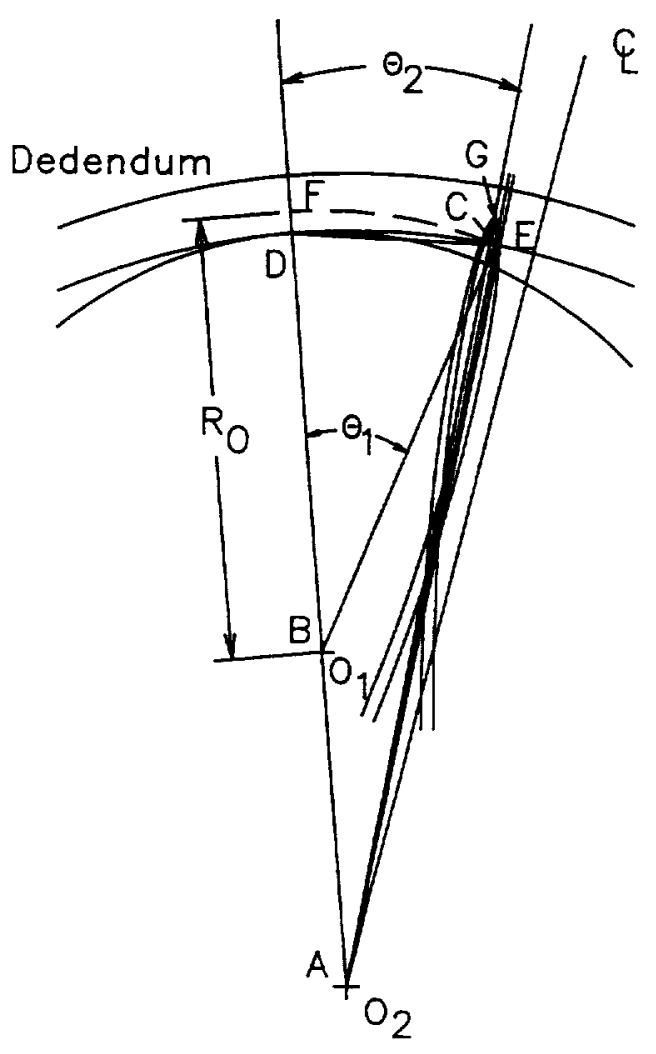

Figure 5 Trochoid Location on the Internal Gear Tooth

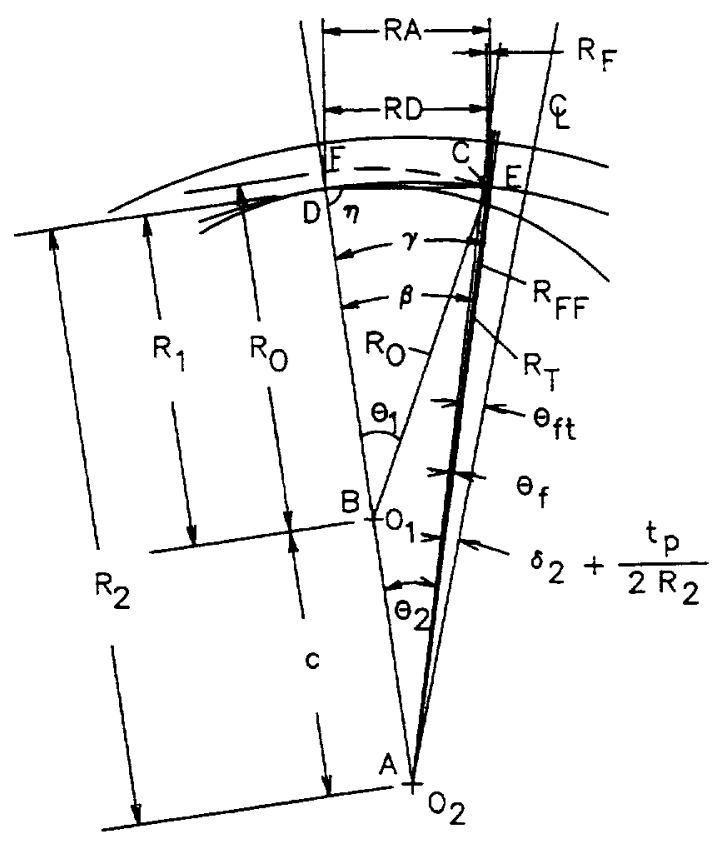

Figure 6 Internal Gear Tooth Trochoid Cutting Point Geometry

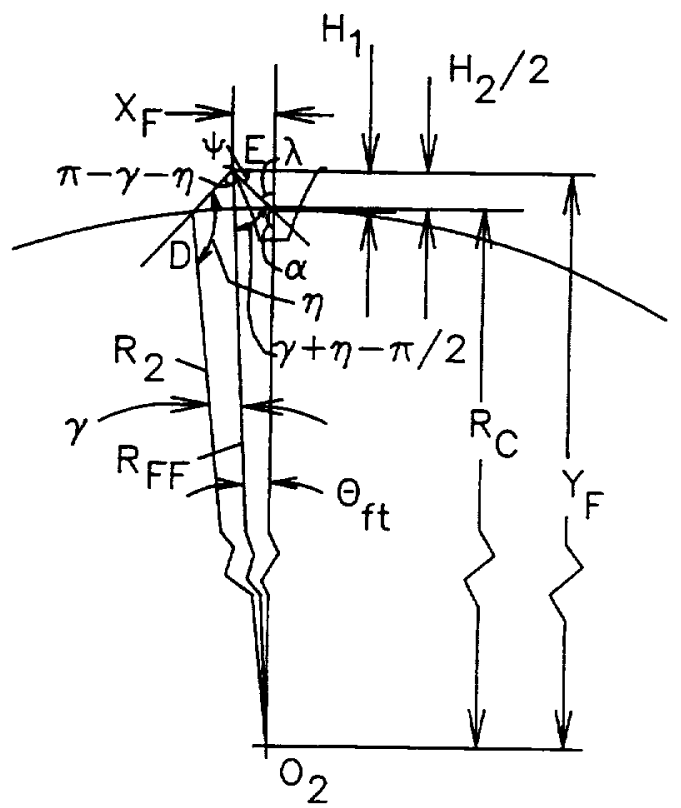

Figure 7 Trochoid Coordinate Angles on the Internal Gear Tooth

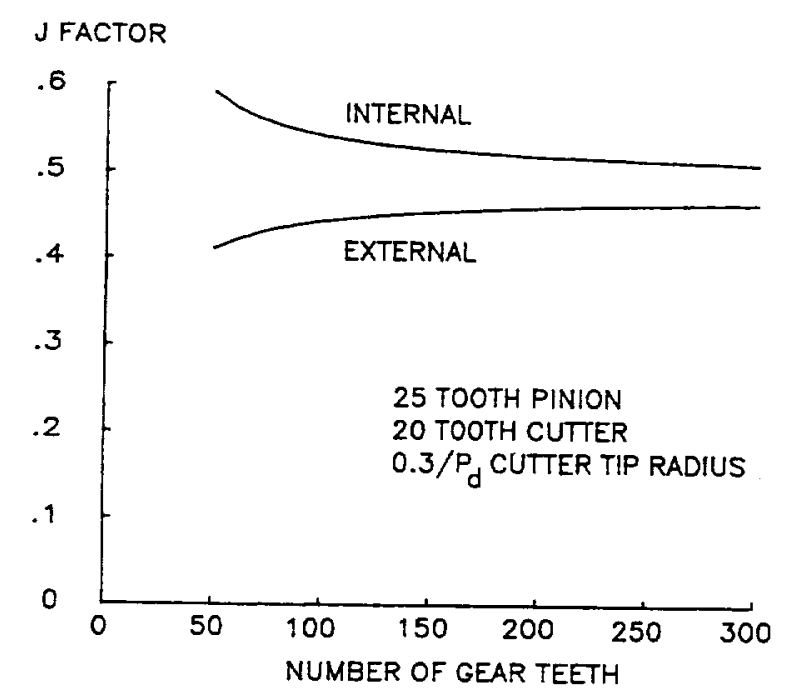

Figure 8 Bending Strength J Factor Values for External and Internal Gears with the Load at the Highest Point of Single Tooth Contact 


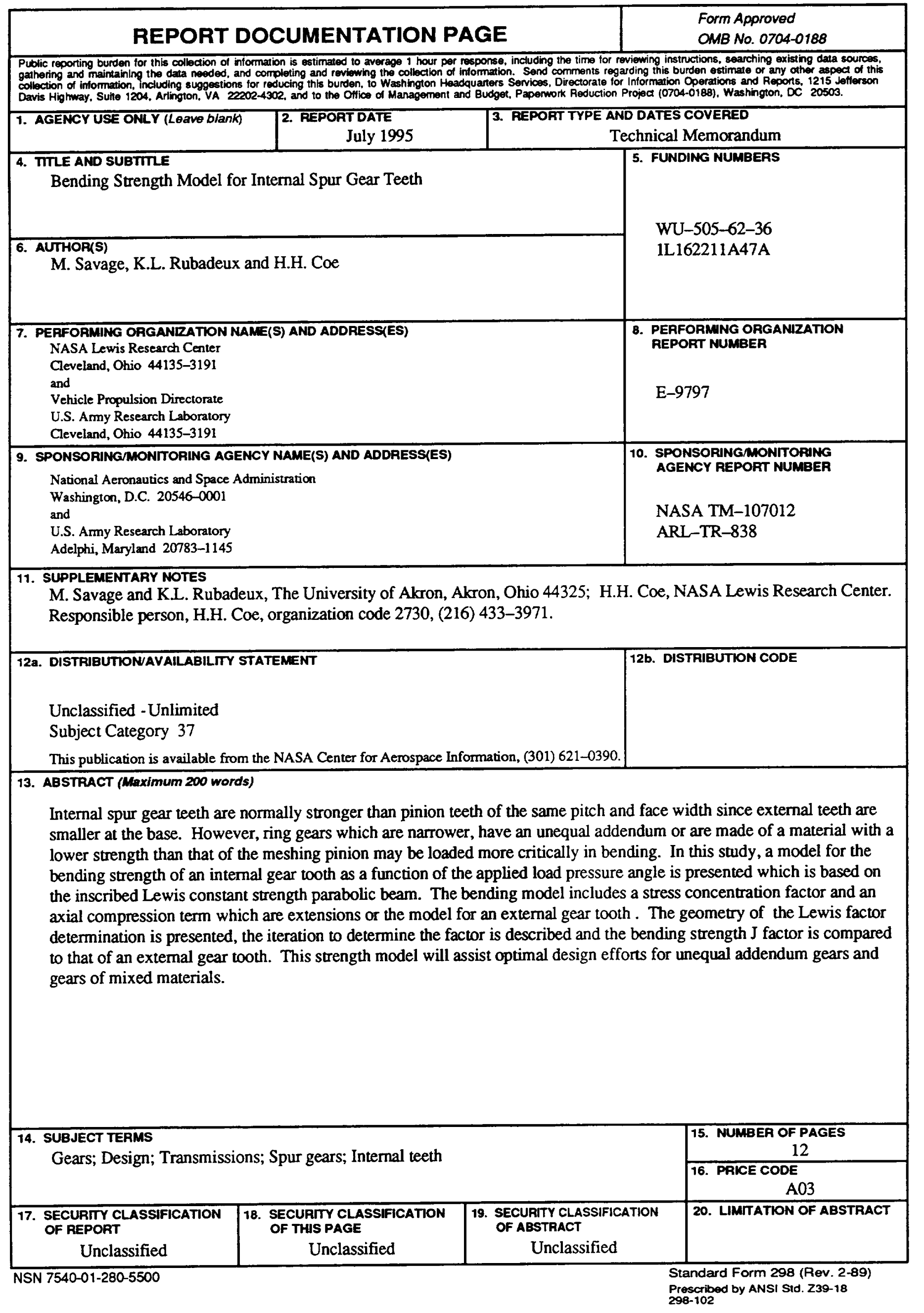


